\title{
Seasonal hydrodynamical features on the continental shelf of Colima (west coast of Mexico)
}

\author{
JOSÉ SALAS ${ }^{1}$, DAMIÀ GOMIS ${ }^{2}$, ARAMIS OLIVOS-ORTIZ ${ }^{3}$ \\ and GERALDINE GARCÍA-URIBE ${ }^{3}$ \\ ${ }^{1}$ Centro de Ecología y Pesquerías-Universidad Veracruzana. Hidalgo 617, Col. Río Jamapa, Boca del Río-Veracruz, \\ México. E-mail: jsalasp39@yahoo.es \\ ${ }^{2}$ IMEDEA (Univ. de les Illes Balears-CSIC). C/ Miquel Marqués, 2107190 Esporles, Mallorca, Spain. \\ ${ }^{3}$ CEUNIVO-Universidad de Colima. Carretera Manzanillo-Barra de Navidad km. 20 C. P. 28860, Colima, México.
}

\begin{abstract}
SUMMARY: Four high-resolution hydrographic surveys were carried out in 2002 on the continental shelf of Colima, Pacific coast of Mexico. The data collected revealed the presence of cyclonic and anticyclonic eddy-like features covering the whole extension of the shelf, which is a rather different pattern from the along-shore general circulation described in previous works. Despite the apparent complexity of the circulation features, the overall shelf-slope exchange pattern is similar in autumn and winter and the opposite in spring. In summer the exchanges also have a similar distribution to autumn and winter, but they are restricted to the upper layers. This suggests that the observed circulation features could result from the interaction between the large-scale seasonal circulation and some kind of local forcing.
\end{abstract}

Keywords: west coast of Mexico, Colima shelf, seasonal hydrodynamics.

RESUMEN: CARACTERÍSTICAS HIDRODINÁMICAS ESTACIONALES SOBRE LA PLATAFORMA CONTINENTAL DE COLIMA (COSTA OESTE DE MÉXICO). - Cuatro estudios hidrográficos de alta resolución fueron realizados en 2002 sobre la plataforma continental de Colima, costa del Pacífico de México. Los datos obtenidos muestran la presencia de remolinos y meandros ciclónicos y anticiclónicos extendiéndose sobre toda la plataforma, lo cual difiere de la circulación general a lo largo de la costa descrita en estudios anteriores. A pesar de la aparente complejidad de la circulación, la distribución de los intercambios entre plataforma y talud es similar en otoño e invierno, y opuesta en primavera. En verano el intercambio también tiene una distribución similar a otoño e invierno, pero ésta se restringe a las capas más superficiales. Parece, por tanto, que las características de la circulación pueden resultar de la interacción del flujo estacional de macro-escala con algún tipo de forzamiento local.

Palabras clave: costa occidental de México, plataforma continental de Colima, hidrodinámica estacional.

\section{INTRODUCTION}

A set of four high-resolution hydrographic cruises were carried out in 2002 along the continental shelf of Colima, west coast of Mexico (Fig. 1). They were undertaken as part of the the ODECOL (Oceanografía Descriptiva del Estado de Colima) project, which aimed at establishing the most important oceanographic features of this area, which has not been studied extensively.
Observations revealed a rather complex structure with a series of cyclonic and anticyclonic eddy-like features covering the whole width of the shelf $(<20$ $\mathrm{km}$ ). This is a very different pattern from the seasonal schematic circulation compiled by Wyrtki (1965) from ship drifts and reviewed by Badan (1997), which essentially consists of two eastern boundary currents flowing along the continental shelf. According to these previous works, the Mexican Current, an extension of the Costa Rica 
Coastal Current represented by a northwestwards flow of warm, salty waters, extends up to the mouth of the Gulf of California from May to December. During this period, the California Current, a southeastward flow of cold, fresh waters, deviates from the coast at about $25^{\circ} \mathrm{N}$, so that it would be absent from the Colima continental shelf. Conversely, between February and April the California Current has been reported to extend southwards down to $\sim 15^{\circ} \mathrm{N}$ (Zamudio et al., 2001), so that it should be observed over the shelf of Colima.

The overall objective of this work is to describe the seasonal hydrodynamic features observed over the continental shelf of Colima. In this context, a first issue to examine will be the seasonal variability of the water mass distribution in the region. A second and perhaps the most important issue will be to compare the variability of the seasonal circulation obtained from the ODECOL cruises, which have a spatial resolution that was not available in the past, with the seasonal patterns of the large scale circulation in the region. In particular, we will focus on the observed strong shelf-slope interactions as an opposite pattern to the assumed along-shore circulation.

\section{THE DATA SET AND DATA PROCESSING}

Hydrographic profiles were collected during four periods of 4 days, each of them centred on one of the seasons of 2002 (ODECOL-1: 12-15 February; ODECOL-2: 8-12 May; ODECOL-3: 1-4 August;
ODECOL-4: 13-16 November). Each cruise consisted of 11 transects of 4 stations oriented perpendicularly to the shore. The distance between stations was $15 \mathrm{~km}$ alongshore and $6 \mathrm{~km}$ cross-shore.

All hydrographic measurements were interpolated from observation points onto grid points using an Optimum Statistical Interpolation scheme (see for instance Bretherton et al., 1976). As the historical database in the region is too poor to compute mean fields, we fitted the observations to a bilinear polynomial, so that the zero-mean increments refer to that linear field. By using a first order polynomial we managed that most of the anisotropy of the total field was captured by the mean field, and the increments showed a more or less isotropic correlation. This is a usual approach followed in many studies of frontal regions (see e.g., Gomis et al., 2001). The correlation scale of the spatial interpolation was set to $20 \mathrm{~km}$ according to correlation statistics. The output grid was rotated $25^{\circ}$ clockwise in order to be more or less parallel to the shore (see Fig. 1). It covers a domain of $33 \times 148 \mathrm{~km}^{2}$ with a grid spacing of 3 $\mathrm{km}$ in both the alongshore and offshore directions; the vertical grid spacing was set to $10 \mathrm{~m}$.

Dynamic height was computed for each hydrographic profile in reference to $205 \mathrm{~m}$. This depth is a compromise between a deeper (and therefore closer to rest) reference level and the intersection with the topography. When computing the geostrophic velocity (by finite-differences from interpolated grid point values of dynamic height fields), we obtained a weak vertical shear below $150 \mathrm{~m}$ except for the

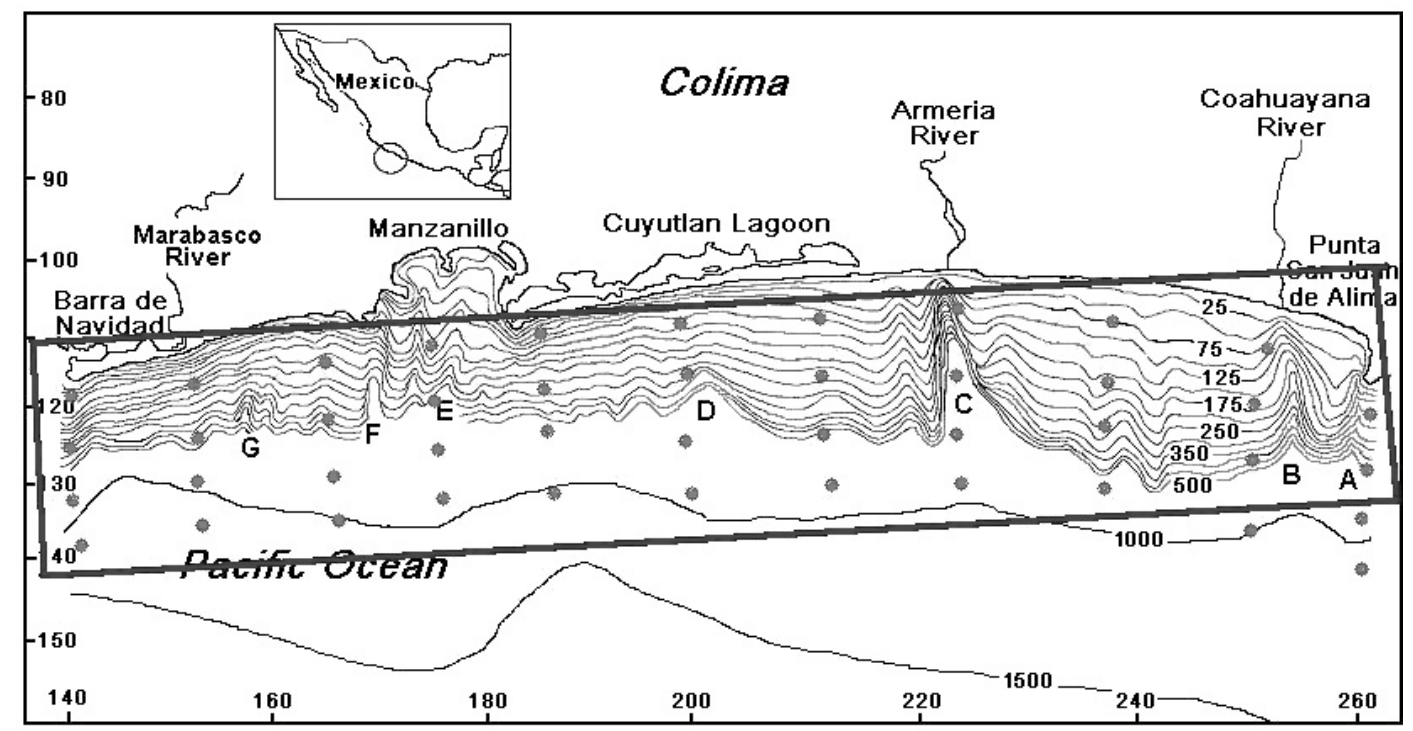

FIG. 1. - The continental shelf of Colima, in the eastern Pacific ocean (axis units are km). The stations of the ODECOL cruises and the interpolation analysis domain have been superimposed. The letters in the image indicate submarine canyons indenting the shelf. 
winter cruise. We estimated that by choosing the reference level at $205 \mathrm{~m}$ we might be underestimating actual velocities in about $10-20 \%$. The winter cruise is the exception: in this case the structures are not limited to upper levels and we admit that we may be underestimating actual velocities by a larger fraction. At stations shallower than the reference depth, the missing water column was extrapolated from nearby stations. This approach cannot be considered reliable when more than half of the column is missing (see for instance Pedder and Gomis, 1998). Therefore, dynamic height was not considered in areas shallower than $100 \mathrm{~m}$ (the distributions are left blank in these shallow areas).

A relevant issue to discuss is whether the sampling strategy is adequate for the purposes of this study, given that tidally generated internal waves have been reported to contaminate hydrographic measurements in nearby regions (Filonov et al., 1996). Long internal waves of 25 to $30 \mathrm{~km}$ are generated on the continental slope between the isobaths of 1000 and $2000 \mathrm{~m}$, but when they travel towards the shore the wavelengths change to range between $100 \mathrm{~m}$ and $8 \mathrm{~km}$ (short internal waves). This implies that in our study region (between the $1000 \mathrm{~m}$ isobath and the shore), wavelengths would be smaller than the separation between stations and therefore can be treated in the same way as small, non-resolved hydrographic structures. Moreover, the amplitude of the reported internal tides is of the order of $20-25 \mathrm{~m}$ (at the thermocline depth), whereas the differences in the thermocline depth observed in our domain are smaller than $10 \mathrm{~m}$. Lastly, if internal tides were severely contaminating our data set, it would be hard to explain why we obtained marked similarities between the circulation in the four seasons. Therefore, although we cannot deny that internal waves do to some extent influence the collected profiles, we consider it unlikely that this influence is large enough to completely distort the computed circulation.

Although internal waves are not expected to severely contaminate the data, they could introduce some aliasing in the recovered fields in the same way as unresolved dynamical scales can do. With the aim of mitigating at least in part this effect, the correlation model of the interpolation scheme was convoluted with a normal-error filter in the way proposed by Pedder (1993). The cut-off wavelength was set to $30 \mathrm{~km}$ (twice the separation distance between adjacent transects), as suggested by Gomis et al. (2001).
A second relevant issue regarding dynamical computations is whether the geostrophic balance can be considered reliable on the shelf-slope. It is clear that the geostrophy is limited by the topographic interaction. However, by blanking the regions shallower than $100 \mathrm{~m}$ we avoid representing features where topographic interaction can be more significant. Unfortunately the lack of ADCP data prevents us from making a direct comparison between geostrophic and in-situ velocity fields.

Finally, we also investigated the wind fields during the periods of the four cruises (including several days before each cruise), in order to check the eventual presence of inertial waves. Results showed that for all periods, winds were less than $5 \mathrm{~m} / \mathrm{s}$, which allows us to discard the generation of significant inertial oscillations.

\section{RESULTS}

\section{The hydrodynamical framework}

Figure 2 shows the density field and the geostrophic circulation at $55 \mathrm{~m}$ depth. The overall circulation pattern is similar at all levels, with maximum velocities reached between the surface and 50 $\mathrm{m}$ (Fig. 3). The strongest circulation features occurred in winter, with mean speeds of $45 \mathrm{~cm} / \mathrm{s}$ at the surface and $25 \mathrm{~cm} / \mathrm{s}$ at $100 \mathrm{~m}$ depth (Table 1). The slowest circulation occurred in summer and autumn, with mean speeds of about $22 \mathrm{~cm} / \mathrm{s}$ in the upper $50 \mathrm{~m}$ and decreased rapidly at lower levels (e.g. $10 \mathrm{~cm} / \mathrm{s}$ at $100 \mathrm{~m}$ ).

The first feature of the circulation worth noting is that no well defined along-shore flow is apparent. Instead, the circulation is dominated by eddy-like features and meanders occupying the whole domain and inducing significant water exchanges between the inner continental shelf and the shelf slope. This is emphasized by the fact that the spatial mean of the along-shore velocity component (component ' $U$ ' in Table 1 ) is only a few $\mathrm{cm} / \mathrm{s}$, with maximum values between 50 and $100 \mathrm{~m}$ in spring and summer and maximum values at the surface in autumn and winter. In summer, for instance, the spatial mean of the along-shore component is positive (south-eastwards), with values of $4 \mathrm{~cm} / \mathrm{s}$ at the surface and a maximum of $12 \mathrm{~cm} / \mathrm{s}$ at $75 \mathrm{~m}$. Conversely, in spring the whole column has northwestward mean alongshore velocities which are only $1.5 \mathrm{~cm} / \mathrm{s}$ at the sur- 

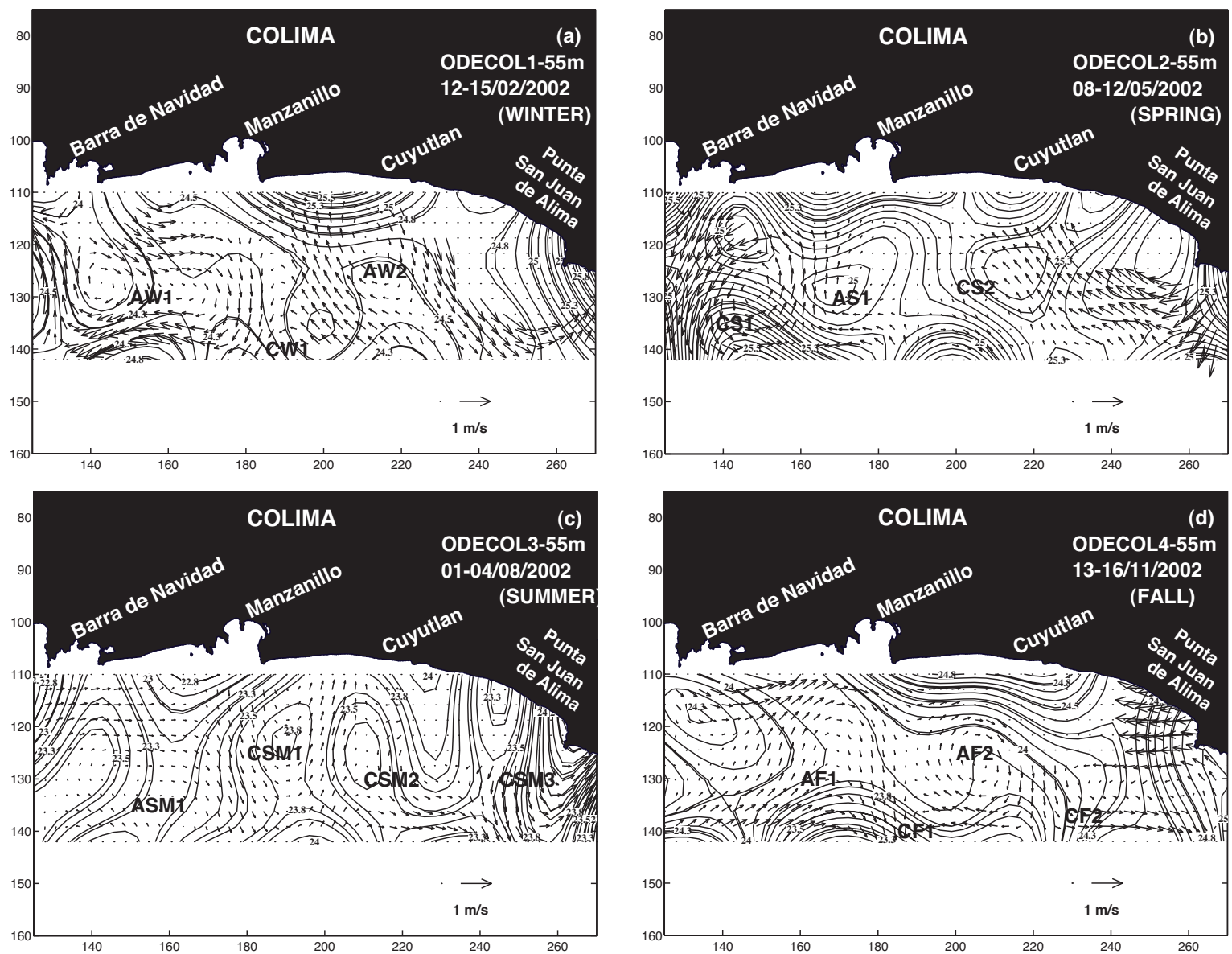

FIG. 2. - Density and geostrophic velocity currents $(\mathrm{m} / \mathrm{s})$ at $55 \mathrm{~m}$ depth. Areas where profiles are shallower than $100 \mathrm{~m}$ have been blanked. Eddies and meanders are named for easier reference in the text: a) Winter; b) Spring; c) Summer; d) Autumn.

face but reach $11 \mathrm{~cm} / \mathrm{s}$ at $75 \mathrm{~m}$. In winter the mean along-shore component is south-eastwards in the upper layers $(8 \mathrm{~cm} / \mathrm{s}$ at the surface decreasing to zero at $40 \mathrm{~m}$ ) and north-westwards at intermediate layers (from 40 to $100 \mathrm{~m}$, with a maximum of $5 \mathrm{~cm} / \mathrm{s}$ at 65 $\mathrm{m})$. Finally, the smallest values are found in autumn: maximum values are found at $45 \mathrm{~m}$ and are less than $8 \mathrm{~cm} / \mathrm{s}$ southeastwards; below $75 \mathrm{~m}$ the mean flow is northwestwards, but is always less than $3 \mathrm{~cm} / \mathrm{s}$.

Cross-shore velocities (component ' $\mathrm{V}$ ' in Table 1) give an idea of the magnitude of shelf-slope exchanges. The spatial mean of the cross-shore component is very small for all seasons, which suggests that exchanges take place in both senses within the sampled region. Nevertheless, it is worth noting that in winter and summer mean values are negative (off-shore sense) through the whole water column, whereas in spring they are all positive (onshore sense). Maximum values are reached in winter, with $4 \mathrm{~cm} / \mathrm{s}$ at $50 \mathrm{~m}$ depth. In spring and summer maximum values are below $2 \mathrm{~cm} / \mathrm{s}$ and again, autumn shows the weakest pattern of the year. In order to quantify the exchanges it is useful to compute the mean absolute value of cross-shore velocities (see Table 1). In winter these are of the order of $25 \mathrm{~cm} / \mathrm{s}$ in the upper $50 \mathrm{~m}$, whereas in spring they are of about $20 \mathrm{~cm} / \mathrm{s}$. In summer and autumn they are significantly smaller: between 12 and $15 \mathrm{~cm} / \mathrm{s}$.

The overall picture therefore is the absence of a well defined along-shore transport and the existence of intense shelf-slope exchanges. In order to place this pattern in a large-scale context (characterized in the literature either by the Mexican Current or the California Current), we will base it on a classical water mass analysis.

Figure 4 shows the TS diagrams of the four cruises. All of them share an overall common structure, with Pacific Equatorial Surface Water (PESW, $23^{\circ} \mathrm{C}<\mathrm{T}<31^{\circ} \mathrm{C}, 34.0<\mathrm{S}<35.0$ ) occupying the surface layers (above $50 \mathrm{~m}$ ) and Equatorial Pacific Water (EPW, $7^{\circ} \mathrm{C}<\mathrm{T}<23^{\circ} \mathrm{C}, 34.5<\mathrm{S}<35.4$ ) lying below. The four cruises also show an interlayer (width of 100- 
TABLE 1. - Spatial mean of the along-shore (UMEAN) and crossshore (VMEAN) velocities $(\mathrm{cm} / \mathrm{s})$ at different depths for the four cruises. The mean of the absolute values of each component (ABSUM and ABSVM) and of the velocity modulus (UVMOD) have also been computed.

LEVEL UMEAN VMEAN ABSUM ABSVM UVMOD

ODECOL -1 (February)

$\begin{array}{lrrrrr}5.0 & 8.5 & -2.2 & 29.5 & 27.8 & 44.7 \\ 25.0 & 6.0 & -2.8 & 27.8 & 26.8 & 42.8 \\ 55.0 & -3.6 & -4.7 & 23.6 & 21.6 & 35.5 \\ 75.0 & -4.7 & -3.4 & 20.6 & 18.6 & 31.3 \\ 105.0 & 0.4 & -2.2 & 16.4 & 14.7 & 24.8 \\ 155.0 & 3.0 & -1.5 & 9.0 & 7.4 & 13.0 \\ 195.0 & 0.2 & -0.3 & 2.6 & 2.4 & 4.1\end{array}$

ODECOL -2 (May)

$\begin{array}{lrrrrr}5.0 & 1.5 & 0.2 & 25.3 & 23.7 & 39.9 \\ 25.0 & -6.6 & 1.1 & 21.7 & 20.5 & 33.2 \\ 55.0 & -10.2 & 1.7 & 16.1 & 15.4 & 24.2 \\ 75.0 & -10.6 & 1.7 & 16.6 & 14.3 & 23.7 \\ 105.0 & -9.5 & 1.0 & 14.1 & 10.9 & 19.0 \\ 155.0 & -4.5 & -0.7 & 6.7 & 5.7 & 9.6 \\ 195.0 & -1.1 & 0.0 & 1.4 & 0.6 & 1.5\end{array}$

ODECOL -3 (August)

$\begin{array}{lrrrrr}5.0 & 3.9 & -0.9 & 16.3 & 14.3 & 23.6 \\ 25.0 & 4.9 & -0.9 & 15.5 & 14.6 & 23.2 \\ 55.0 & 6.5 & -1.1 & 14.2 & 9.7 & 19.0 \\ 75.0 & 11.6 & -1.8 & 14.7 & 8.3 & 18.2 \\ 105.0 & 8.3 & -1.5 & 11.7 & 5.3 & 13.6 \\ 155.0 & 1.7 & -0.3 & 4.4 & 1.9 & 5.2 \\ 195.0 & 0.0 & 0.0 & 0.8 & 0.5 & 1.1\end{array}$

ODECOL -4 (November)

$\begin{array}{lrrrrr}5.0 & -4.4 & 1.0 & 16.0 & 13.5 & 23.3 \\ 25.0 & 2.0 & 0.0 & 15.1 & 13.2 & 22.5 \\ 55.0 & 6.8 & -0.1 & 15.2 & 10.9 & 20.4 \\ 75.0 & -1.8 & 0.6 & 10.9 & 7.4 & 14.7 \\ 105.0 & -3.0 & -0.4 & 6.6 & 4.3 & 8.9 \\ 155.0 & -1.6 & -0.7 & 3.3 & 2.3 & 4.3 \\ 195.0 & -0.2 & 0.0 & 0.5 & 0.4 & 0.7\end{array}$

$150 \mathrm{~m}$ ) of Subtropical Subsurface Water (STSsW, $12^{\circ} \mathrm{C}<\mathrm{T}<14^{\circ} \mathrm{C}, 34.7<\mathrm{S}<35.0$ ), which is always located between 100 and $250 \mathrm{~m}$ depth. There are, however, a few exceptions to this overall structure.

The first exception is that in autumn (Fig. 4d), the surface layer has a significantly lower salinity, which makes it fall within the range of Pacific Tropical Surface Water (PTSW, $25^{\circ} \mathrm{C}<\mathrm{T}<31^{\circ} \mathrm{C}$, $33.0<\mathrm{S}<34.0)$. However, a more likely explanation than the presence of PTSW is that the observed low salinities are the result of mixing between PESW and fresh water from river run off. Of the twelve tropical cyclones reported over the Pacific coast of Mexico (Servicio Meteorologico Nacional), two of them ('Julio' in September and 'Kenna' in October) resulted in heavy rain over the region of Colima. The precipitation recorded in September and October in
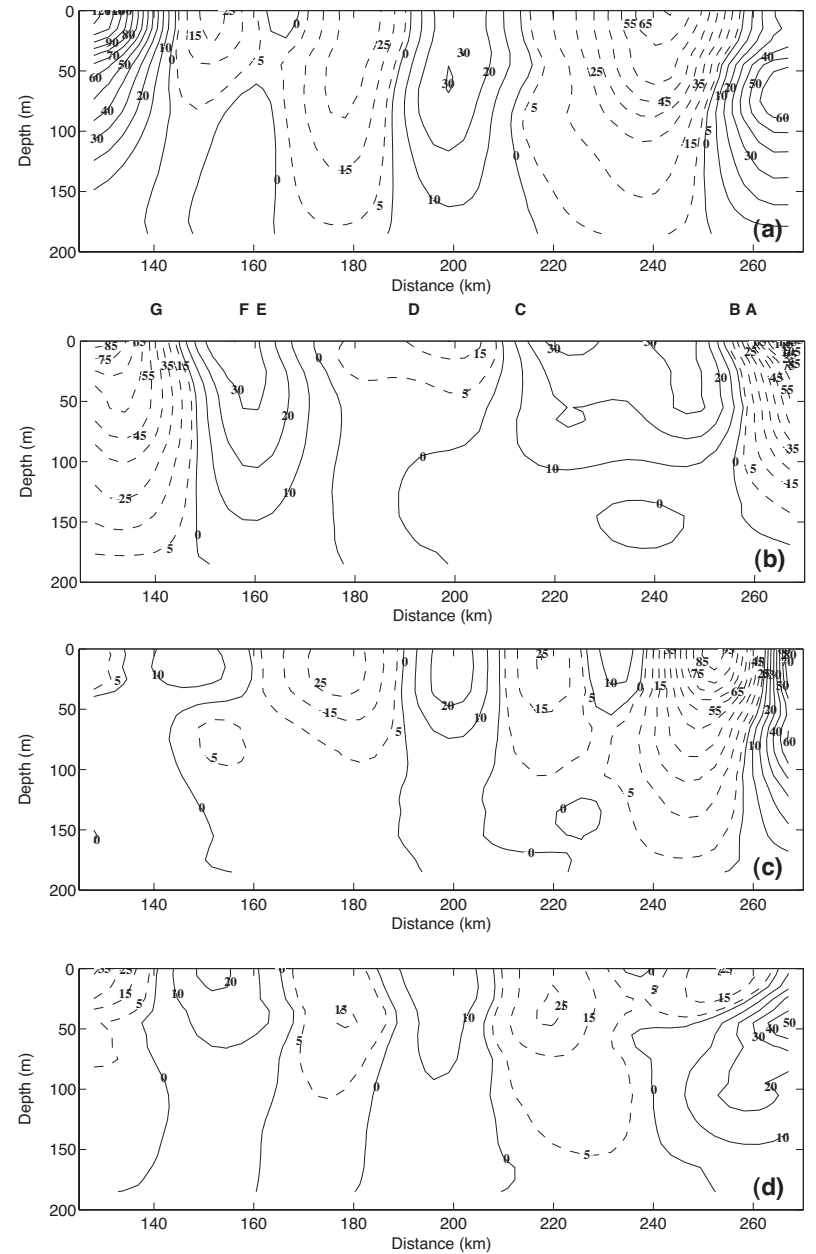

FIG. 3. - Along-shore vertical section located at about half way up the sampled domain (along $\mathrm{y}=130 \mathrm{~km}$, see Fig. 1). The contoured field is the cross-shore geostrophic velocity $(\mathrm{m} / \mathrm{s})$, with positive (negative) values indicating onshore (offshore) flows. The locations of the axes of canyons A-G shown in Fig. 1 have been marked in the upper panel. a) Winter. b) Spring. c) Summer. d) Autumn.

Colima State was $229 \mathrm{~mm}$ and $174 \mathrm{~mm}$ respectively, which are significantly higher than the climatological values (about $170 \mathrm{~mm}$ and $70 \mathrm{~mm}$ respectively). Moreover, in November the precipitation was higher than usual (74 $\mathrm{mm}$ compared to the climatological value of $20 \mathrm{~mm}$ ). These data support the role of river run off in the low surface salinity observed in November. The second and perhaps most important exception to the overall water mass structure described above is that the winter TS diagram (Fig. 4a) and, to a lesser extent, the spring diagram (Fig. $4 \mathrm{~b})$, also reveal the presence of a layer of Californian Current Water $\left(\mathrm{CCW}, 12^{\circ} \mathrm{C}<\mathrm{T}<25^{\circ} \mathrm{C}, 33.5<\mathrm{S}<34.5\right)$ in between the PESW and the EPW. This layer is located in between 30 and $60 \mathrm{~m}$ depth, and is wider on the NW side of the domain than on the SE side. In spring, the presence of California Current Water is restricted to a few stations located on the open-sea 

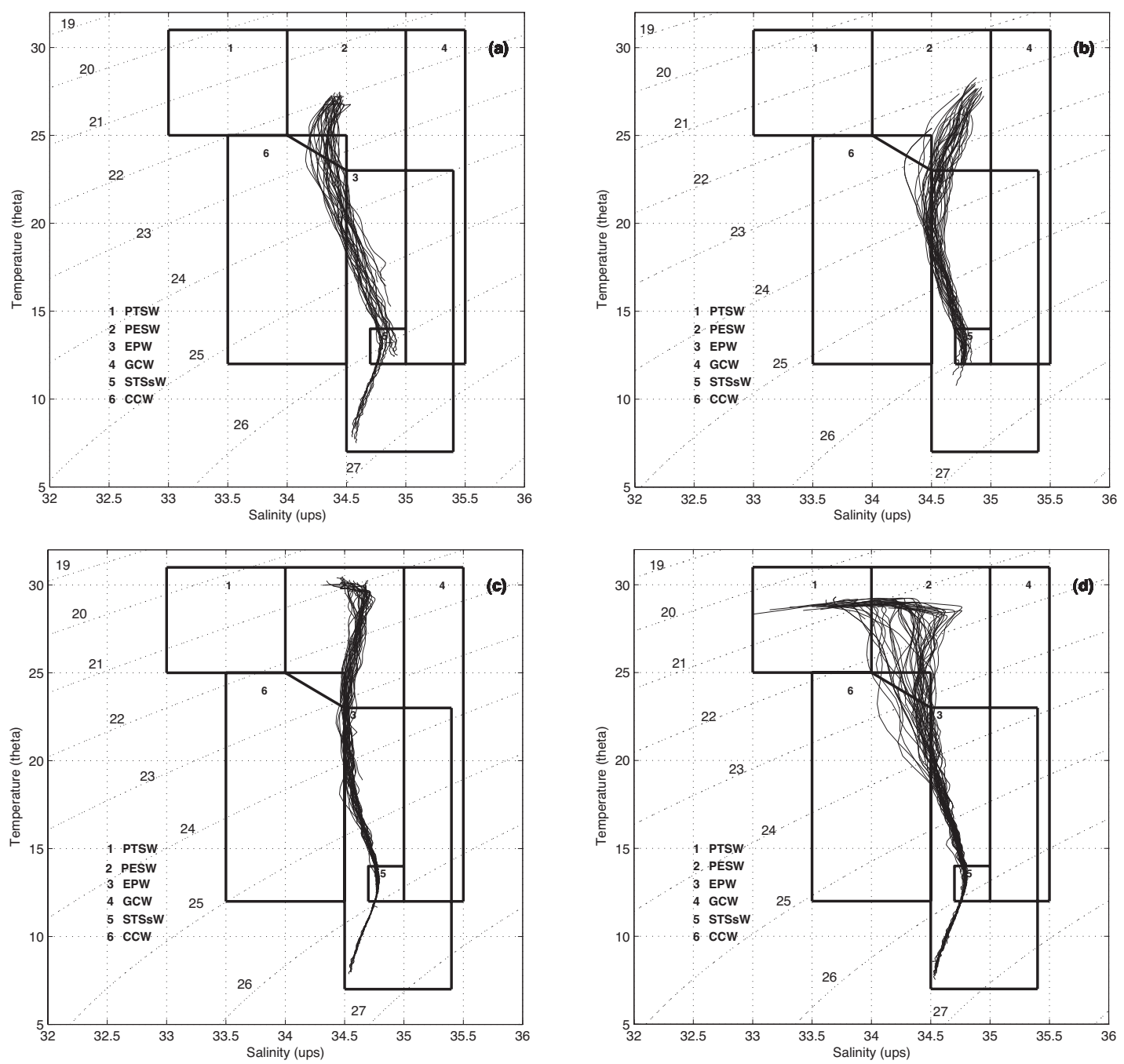

FIG. 4. - TS-diagrams of the four ODECOL cruises: a) Winter; b) Spring; c) Summer; d) Autumn.

side of the sampled domain, which would indicate that the $\mathrm{CC}$ is detaching from the shore.

A feature worth noting is that some profiles show significant differences at intermediate depths (see diagrams $4 \mathrm{a}, \mathrm{b}, \mathrm{c}$ below $15^{\circ} \mathrm{C}$ ), which might suggest there are spurious profiles that need to be corrected or deleted. A way to assess whether the observed differences are because they are real or due to instrumental noise is to look at the spatial distribution of the 'anomalous' profiles. It turns out that they correspond to adjacent stations, which, even though it does not allow us to discard a sensor malfunction, suggests the existence of actual differences in between different regions of the domain.

Therefore, results support the fact that the large scale pattern is largely dominated by the Mexican Current which flows northwestwards carrying waters from lower latitudes. In winter, however, it seems that the California Current could reach the region as a subsurface tongue, which would detach from the shore in spring. The overall pattern is in agreement with previous studies (Badan, 1997), which suggest that the Californian Current only occasionally reaches the Colima region between February and June.

\section{The mesoscale circulation features}

In winter, the main circulation features are two anticyclonic features, (denoted by AW1 and AW2 in Fig. 2a) and one structure that is not well defined (denoted by CW1). AW1 is actually the lowest signature of a subsurface tongue of the California Current water entering the domain from the northwest. The typical diameter of the observed eddy-like features is in between 20 and $40 \mathrm{~km}$. 
During spring (Fig. 2b) the overall circulation has practically been replaced. Hence, the anticyclonic structure AW1 of Fig. 2a has become a well defined cyclonic eddy, CS1. It is worth noting that the density field still shows a tongue of light water collocated with CS1. However, from $60 \mathrm{~m}$ downwards a marked dome of dense water induces the observed cyclonic curvature. Finally, AW2 and CW1 have been replaced by patterns that are not well defined with some cyclonic (CS2) and anticyclonic curvature (AS1) respectively.

In summer (Fig. 2c), the flow is significantly weaker and the density field shows a pattern fragmented into smaller scale structures. As in spring, the circulation is governed by the density structure of subsurface layers, which is also dominated by an eddy-like pattern. At first sight the summer spatial pattern does not resemble the winter pattern, but it will be shown later on that the shelf-slope exchanges occur at the same locations as they do in winter.

In autumn (Fig. 2d) the structures again resemble the winter features (Fig. 2a). In particular, there is an anticyclonic structure that is not well defined to the west of the domain (AF1) which is even less clear than AW1. The same holds for the cyclonic feature CF1. Conversely, well defined structures occupy the eastern side: AF2, located in the same place as AW2; and CF2, located on the shelf break rather than on the inner shelf.

\section{Evidences of local forcing}

Some similarities have been described between the circulation patterns of the four seasons. These are highlighted when focusing on the shelf-slope exchanges. Figure 3 shows a NW-SE cross section of geostrophic velocity located at about the middle of the sampled domain. Positive values are onshore flows, whereas negative values denote offshore flows. A first feature worth noting is that the vertical extension of the structures is different for each season. In winter, they clearly reach $200 \mathrm{~m}$ and might extend below that level if they were not forced to close due to the choice of the reference level at that depth. In spring and autumn their vertical extension is between 100 and $150 \mathrm{~m}$, and they are shallower in summer: none of them exhibits significant velocities below $100 \mathrm{~m}$.

Most importantly, in terms of the forcing mechanism, the location of the onshore and offshore inflows seems to be maintained throughout the seasons. Namely, in winter, summer and autumn the positive and negative flows are located in almost exactly the same place, whereas in spring the flow has an overall opposite sense. These similarities point to some kind of local mechanism, such as a permanent wind regime or a topographic forcing.

\section{DISCUSSION}

During 2002, the main hydrographic variables measured on the continental shelf of Colima showed a complex spatial pattern consisting of a series of mesoscale meanders and anticyclonic and cyclonic eddies. The water masses found on the continental shelf are associated with the large-scale surface flow of the California Current and the Mexican current (Wyrtki, 1965; Badan, 1997). However, there is no well defined along-shore transport, as could be expected from these two currents, but an intense shelf-slope exchange promoted by mesoscale structures. Another relevant result is that we have confirmed that the California Current can reach the continental shelf of Colima. Namely, California Current Water has been clearly detected forming a subsurface layer (30-60 m) in winter and, to a lesser extent, in spring.

Eddies propagating along the continental shelf of the eastern boundary of the Mexican Pacific Ocean have been reported to generate mainly in the Gulf of Tehuantepec as a response of the surface ocean to the wind curl (Stumpf and Legeckis, 1977; SalasPérez, 2002). However, eddies moving along the shelf could also be generated by a coastal jet induced by the interaction of the Mexican Current with the downwelling current of Kelvin waves (Zamudio et al., 2001). In these cases, when this jet becomes baroclinically unstable, the Rossby number in terms of the planetary $\beta$ term reaches a value of 10 (Zamudio et al., 2001). These eddies are characterized by their large radius ( $r>100 \mathrm{~km}$ ), which is three times larger than the radius of deformation in the region (about 15-40 km), swirl and translation velocities of $\sim 50 \mathrm{~cm} / \mathrm{s}$ and $8-20 \mathrm{~km} /$ day, and a vertical structure developed down to 150-250 m (SalasPérez, 2002). The eddies observed in the seasonal fields of 2002, however, have a radius that is approximately equal to the internal radius of deformation of the region (15 to $40 \mathrm{~km}$ ), and therefore the generation mechanism can hardly be associated with the one mentioned above. Then the origin of the eddies is not clear. 
An interesting feature observed in the geostrophic field is the reversal of the shelf-slope exchanges in spring with respect to the other seasons. Although it would be tempting to associate this reversal with the strengthening of the California Current in its southward path to the equator, our results indicate that in spring the California Current is already detaching from the shelf and therefore weakening within the sampled region. The fact that the vertical dimension of the velocity structures is shallower in summer than in the other seasons is interpreted as a response to the seasonal shoaling of the picnocline.

But perhaps the feature of the obtained results most worth noting is that the location of the maximum shelf-slope exchanges coincides all year round (in spring with an opposite sense with respect to the other seasons). This points towards local forcing as the generation mechanism of the eddies and meanders. As it has been argued above, the circulation is clearly driven by the structure of the density field below $50 \mathrm{~m}$ depth, which suggests we should discard the wind as the main forcing. The topographic forcing then appears to be the most likely mechanism.

As shown in Figure 1, the Colima's narrow continental shelf is indented by significant topographic features. A ridge and groove system is cut by a series of narrow submarine canyons with "v" shaped mouths situated downstream of rivers. Klinck (1996) classified submarine canyons as narrow or broad, comparing their width with the internal radius of deformation. According to his study, the submarine canyons of this area are narrow, because their width is smaller than the local internal radius of deformation. For (left bounded flow, or favourable upwelling ) canyons with a width less than or equal to the internal radius of deformation, the circulation above the canyon tends to be cyclonic, with a diameter equal to about 2 times the internal radius of deformation (Klinck, personal communication).

In order to check the eventual role of the canyons on the shelf-slope exchange reported in Figure 3, the locations of the canyons have been marked in Figure 3a. As it can be seen, the cross-shore exchanges change sign more or less where the canyons' axes are located. That is, the centre of mesoscale structures would more or less coincide with the location of the canyons.

Therefore, the fact that the available data set has a higher resolution than previous samplings has allowed us to detect the existence of significant mesoscale features over the Colima shelf. In addition, the fact that four seasons are covered has allowed marked similarities between the circulation features throughout the year to be detected. However, in order to make better based conclusions, a higher resolution and almost synoptic samplings complemented by time series would be required, in particular if the topographic interaction is to be studied. In addition, numerical models including realistic topographic forcing could reinforce the analysis.

\section{ACKNOWLEDGEMENTS}

Thanks to the Centro de Ecología y Pesquerías of the Universidad Veracruzana, for supporting this research through the Project UVER-PTC-98. We would also like to thank the reviewers for helping to improve this manuscript. We also thank to the Secretaría de Marina Armada de México since their program ODECOL was derived this publication, and our recognition to the reviewers for helping to improve this manuscript.

\section{REFERENCES}

Badan-Dangon, A. - 1997. La Corriente Costera de Costa Rica en el Pacifico Mexicano. In: M. Lavín (ed.), Contribución a la Oceanografía Física en México. Monografía 3, pp. 99-113 Unión Geofísica Mexicana.

Bretherton F. P., R. E. Davis and C. B. Fandry. - 1976 A technique for objective analysis and design of oceanographic experiments applied to MODE-73. Deep-Sea Res., 23: 559-582.

Filonov A., C. Monzon and I. Tereshchenko. - 1996. Acerca de las condiciones de generación de las ondas internas de marea en la Costa Occidental de México. Cienc. Mar., 22(3): 1-18

Gomis, D., S. Ruiz and M.A. Pedder. -2001 . Diagnostic analysis of the 3D ageostrophic circulation from a multivariate spatial interpolation of CTD and ADCP data. Deep-Sea Res. I, 48: 269-295.

Klinck, J.M. - 1996. Circulation near submarine canyons. J. Geophys. Res., 101: 1211-1223.

Pedder M.A. - 1993. Interpolation and filtering of spatial observations using successive corrections and gaussian filters. Mon. Weather. Rev., 121: 2889-2902.

Pedder M. A. and D. Gomis. - 1998. Application of EOF Analysis to the spatial estimation of circulation features in the ocean sampled by high-resolution CTD samplings. J. Atmos. Ocean Tech., 15(4): 959-978.

Salas-Pérez, J.J. - 2002. Mesoscale gyres generated along the pacific eastern boundary: during normal and abnormal (the El Niño and La Niña events) years (abstract), III Coloquio sobre Oceanografia del Pacifico Oriental.

Stumpf, G.H. and R.V. Legeckis. - 1977. Satellite Observations of Mesoscale Gyres Dynamics in the Eastern Tropical Pacific Ocean, J. Phys. Oceanogr., 7: 648-658.

Zamudio, L., A.P. Leonardi, S.D. Myers and J.J. O'Brian. - 2001. ENSO and eddies on the southwest coast of Mexico, Geophys. Res. Lett., 28(1): 13-16.

Wyrtki, K. - 1965. Surface currents of the Eastern Tropical Pacific Ocean, Bull. II-ATTC., 9(5): 63-97.

Received June 29, 2005. Accepted May 23, 2006.

Scient. ed.: J. Font.

Published online November 15, 2006. 